\title{
Doğuştan çarpık ayak rezidüel deformitelerinde kemiksel girişimler
}

\author{
Bone procedures for residual or recurrent deformities \\ in patients with treated congenital clubfoot
}

\author{
Nusret Köse \\ Eskişehir Osmangazi Üniversitesi Tıp Fakültesi, Ortopedi ve Travmatoloji Anabilim Dalı, Eskişehir
}

\begin{abstract}
Doğuştan çarpık ayakta Ponseti yönteminin doğru uygulandığı hastalarla cerrahi uygulanan hastaların bir kısmında residüel biçim bozuklukları kalabilmekte ya da rekürrens (biçim bozukluğunun yinelemesi) görülebilmektedir. Küçük çocuklarda deformiteler, yeniden Ponseti tekniği uygulanarak düzeltilmeye çalışılmalıdır. Diğerlerinde nasıl bir sağaltım yöntemi uygulanacağına, yaş, etiyoloji, fizik bakı ve radyolojik incelemelerle deformiteler ortaya konup karar verilir. Köse ve arkadaşları, her üç küneiform ve küboidden geçen, kavovarus ve ekinus deformitesini düzeltecek transvers midtarsal osteotomi tekniğini tanımlamışlardır. Varusu düzeltmek ve lateral ile mediyal kolonu eşitlemek için, lateralden çıkarılan kama mediyale konulur. Bu teknik, ayak arkasındaki deformiteyi düzeltmez; ancak ayak önü adduksiyon, ayak ortası supinasyon ve kavusun bütün hastalarda düzeldiği görülmüştür. Öte yandan, bu yöntemde eklemler kat edildiği için, gelecekte artroz olasılığı vardır. Hasta dört yaşından daha büyük olduğu takdirde, kemik iyileşmesinin daha iyi olması mümkündür.
\end{abstract}

Anahtar sözcükler: çarpık ayak; ayak deformiteleri, doğumsal; residüel deformite; ortopedik cerrahi
Equinovarus deformity may remain or may recur following casting and/or a variety of minimal or extensive surgeries. Repeated casting should be the initial management for the recurrent clubfoot in the young. Otherwise, age, etiology, physical examination, and radiographic examination are used in combination to assess and treat residual or recurrent deformity. Each foot must be considered a unique problem with an individual treatment history and remaining deformities. Kose et al. reported transverse midtarsal osteotomies performed through all three cuneiforms and cuboid to correct forefoot varus and equinus. A wedge from the lateral column was removed and placed into the medial column to correct varus and adjust the length. This technique do not affect the residual hindfoot deformity, but forefoot adductus, midfoot supination, and cavus were corrected in all patients. Since the procedure crosses joints, the possibility of future arthrosis exists. Patients should be older than 4 years to allow for better bone healing.

Key words: clubfoot; foot deformities, congenital; residual deformity; orthopedic surgery
Ç arpık ayak değişik derecelerde ciddiyeti olan bir hastalık spektrumudur. Alt ekstremitede en sık görülen doğumsal anomalilerden birisidir. En kolay düzelen tipi, pozisyonel/postüral olanıdır; en sık görüleni ise idiyopatik tiptir. Prognozu en sıkıntılı ola$\mathrm{nı}$, sendromik ve nörolojik nedenlere bağlı görülebilen, sekonder tiptir. ${ }^{[1-4]}$ Ponseti, 1940'lı yıllarda manipülasyon ve alçı yöntemini kullanmaya başlamış olsa da, bu teknik 90'lara kadar popüler olamamıştır. Yıllarca tercih edilen yöntem, cerrahi yollarla yapılan yumuşak doku gevşetme girişimleri olmuştur. Günümüzde ortopedik cerrahların çoğu, doğuştan çarpık ayakta başlangıç tedavisinin cerrahi olmayan, ardışık manipülasyon ve alçılama olduğu konusunda görüş birliğindedirler. Ponseti yöntemi, oldukça başarılı ve popüler bir seçenek haline gelmiştir. Uygulamaya, yaşamın ilk günlerinde başlanmalıdır. Böylece, bağları, eklem kapsülünü ve tendonları oluşturan fibroelastik yapıdaki bağ dokusunun uzayabilme özelliğinden yararlanılmış olur. Bu olgularda sağaltımın amacı; normal işlevlerini yerine getirebilen, ağrısı olmayan, yere düz basabilen, fleksibilitesini sürdürebilen, normal ayakkabı giyebilen ayaklar elde etmektir. Çarpık ayak olgularının çoğu, eğer doğumdan hemen sonra tedaviye başlanmışsa, uygun yapılmış ardışık manipülasyon ve alçılama ile düzelir. Manipülasyon ve alçılama tedavisinde başarısızlığın nedeni, genellikle, cerrahın deformitenin gerçek kinematik ve patolojik anatomisine ait yeterli bilgiye sahip olmamasıdır.

- İletişim adresi: Prof. Dr. Nusret Köse, Eskişehir Osmangazi Üniversitesi Tıp Fakültesi, Ortopedi ve Travmatoloji Anabilim Dalı, Eskişehir Tel: 0222 - 2392979 e-posta: drnkose@gmail.com

- Geliș tarihi: 25 Mayıs 2015 Kabul tarihi: 25 Mayıs 2015 
Ponseti yönteminin doğru uygulandığı hastaların bir kısmında da residüel (kalıcı) biçim bozuklukları olabilmekte ya da rekürrens (biçim bozukluğunun yinelenmesi) görülebilmektedir. Literatürde, olguların yaklaşık \%25'inde, sıklıkla ayak önü adduksiyon ve supinasyon, çok nadir olarak ayak arkası varus ve ekinus deformiteleri görülebildiği bildirilmiş olmakla birlikte, tam bir posteromediyal cerrahi gevşetme gereken olguların oranı \%5'ten azdır. ${ }^{[5,6]}$ Cerrahi tekniklerdeki gelişmelere ve tüm özene karşın, çarpık ayak cerrahisi sonrası residüel deformiteler de nadir değildir. Deneyimli cerrahların serilerinde dahi, çarpık ayağın yinelediği ya da yeni bir cerrahi girişim gerektirdiği görülmektedir. Çarpık ayak residüel biçim bozukluklarının tedavisi, pediatrik ortopedinin en zor sorunlarından biridir. Cerrah, genellikle, bir veya daha çok cerrahi girişim uygulanmış ve tam olarak düzelmemiş bir ayakla karşı karşıyadır. Biçim bozukluğu daha belirgin ve rijid/ sert bir hal almıştır. İyi sonuç elde etmek, özelllikle çok sayıda opere edilmiş ayaklarda zordur. Önceki girişimlere bağlı cilt ve yumuşak doku, skar dokusu, özellikle ayağın iç kısmında düzeltmeyi güçleştirir; reoperasyon risklidir. Ciltte, kemikte ve kıkırdakta, nekrozlar ve yara yeri enfeksiyonları, görülebilen komplikasyonlardır.

Çarpık ayakta biçim bozukluğunu yaratan süreçlerle bunun yinelenmesine neden olan süreçler aynı olmakla birlikte, birçok olguda cerrahi girişimin yetersiz ya da tersine aşırı yapılmasının, biçim bozukluklarının ortaya çıkmasında rolü vardır. Bazen, önceden uygun bir biçimde tedavi edilen bir ayakta; çocuğun büyüme hızı, internal tespitin yetersizliği ya da cerrahi sonrası dönemde uygulanan yanlış alçılama, ayaktaki biçim bozukluğunun yinelemesinde rol oynayabilmektedir.

Ponseti uygulaması sonrası sık görülebilen ayak önü adduksiyon/supinasyon deformitesi dışında, cerrahi uygulamalar sonrası sık görülebilen diğer biçim bozukluğu, ayağın kavovarus deformitesi ve ayak önü adduksiyon, ayak ortası supinasyon ve ayak arkası orta derecede varus kombinasyonu ile karakterize olan "fasulye biçiminde ayak" deformitesidir. Pes planus, ekinus ve izole topuk varusu, daha az görülen izole deformitelerdir. Bu deformiteler, yürüyüşü, ayağın yere basmasını ve ayakkabı giyimini olumsuz etkiler. Sonuçta, çocukta günlük aktiviteler ve spor kısıtlanır; bu da sıkıntılara neden olur.

Residüel çarpık ayaklı olgularda, ayağın arkası, ortası ve önü ayrı ayrı dikkatlice incelenip, deformitenin hangi kısımlarının kabul edilebilir olduğuna ve hangilerinin düzeltilmesi gerektiğine karar verilir. Karar vermede, basarak ayak ön-arka ve yan grafiler ile kalkaneus aksiyel grafisi yardımcı olur. Talokalkaneal açı, tibiokalkaneal açılar, metatarsus adduktus ve talar deformiteler, radyolojik olarak değerlendirilir. Ayak arkası incelenirken, ayak bileği hareket genişliğine, talus ve kalkaneusun paralelliğine, talustaki şekil bozukluğuna, daha sonra da topuğun varus, valgus, ekinus ya da kalkaneus pozisyonunda olup olmadığına; ayak ortasında, naviküler kemiğin talus başı ile ilişkisine, mediyal, dorsal ya da dorso lateral olup olmadığına ve küboidin kalkaneus ile olan ilişkisine; ayak önünde ise adduksiyon, supinasyon, pronasyon ya da abduksiyon olup olmadığına bakılır.

Bu hastalarda tamamen normal bir ayak elde edilemeyeceği için, tedavide amaç, ağrısız bir yürüyüşün elde edildiği, yere düz basan, göreceli olarak düz bir ayak elde edilmesi ve ayak haraketlerinde daha ileri hareket kısıtlılığının olmamasıdır. Deformitenin dinamik ya da sabit olup olmadığını belirlemek, tedavileri oldukça farklı olduğu için, çok önemlidir. Dinamik deformiteler pasif olarak düzeltilebilir. Ayak önünde dinamik adduksiyon, yürüme sırasında supinasyon deformitesi ve dinamik kavovarus deformitesi, özellikle tibialis anterior ve tibialis posterior ile peroneal kaslar arasındaki fonksiyon bozukluğuna ya da koordinasyon bozukluğuna bağlıdır. Tibialis anterior kası, birçok çarpık ayak olgusunda göreceli olarak daha normaldir ve ayağa kuvvetli inversiyon ve supinasyon uygular. Tibialis posterior ve peronealler ise aksine, genelde zayıftır. Bu olgularda, tibialis anterior tendonunun ayak sırtına, 2. ya da 3 . küneiforma transpozisyonu ya da küboide split tibialis anterior transferi ile düzeltme sağlanabilir.

Sabit metatarsus adduktus deformitesinde, olguların çoğunda, ilk cerrahi girişim sırasında kalkaneoküboid gevşetme yapılmamıştır. Metatarsal osteotomilerle, bazen de mediyal küneiform ve lateral küboid osteotomi kombinasyonu ile düzeltme yapılabilir. Sabit kavovarus deformitesinde en sık neden, plantar fasya kontraktürüdür. Bu deformitenin, plantar fasya gerginliğine mi yoksa sabit topuk varusuna mı bağlı olduğu, blok testi ile ayırt edilebilir. Buna göre, plantar gevşetme ya da yumuşak doku gevşetmeleri ve tendon transferleri ile kemik girişimleri uygulanır.

Birçok yineleyici deformitede, ayağın mediyal kolonu kısalmış ve lateral kolonu uzamıştır. Sabit deformitelerin olduğu bir residüel çarpık ayakta, mediyal kolon (talus, naviküler, küneiformlar ve ilk üç metatarsal) ve lateral kolon (kalkaneus, küboid, ve 4.-5. metatarsallar), dengelenerek, ayağın plantigrad olması, kas kuwetleri de dengelenerek ayağın plantigrad kalması sağlanır. Fasulye biçimindeki ayak deformitesi, küboid dekansellasyonu ya da mediyal küneiform açılan kama osteotomisi ile mediyal kolonun uzatılması ve küboidin kapanan kama osteotomisinden yarar görebilir.

Subtalar eklemin aşırı gevşetilmesi, özellikle talokalkaneal interosseöz bağın tam olarak kesilmesi ile, arka ayakta aşırı düzelme görülür. Kalkaneusun laterale 
translasyonu ile birlikte görülen ciddi pes planus, oldukça önemli bir sorun yaratabilir. Bu olgular, kalkaneal slayding osteotomiden yarar görebilir. Topuk varusunda, Dwyer kalkaneus osteotomisi (lateral kapanan kama); residüel topuk ekinusu için, kalkaneus tendon uzatması ve bazen de posterior gevşetme; sabit ekinus deformitesinde, Lambrinudi artrodezi; her üç komponentin olduğu deformitelerde ise, 10 yaşından büyük çocuklarda, üçlü artrodez gerekebilir. Bu çocuklara, 6-12 yaş arasında llizarov tekniği uygulanabilir. ${ }^{[7-11]}$

Residüel çarpık ayak biçim bozukluklarının düzeltilmesi için, yukarıda belirtilen birçok girişim kullanılmıştır. Bu cerrahi girişimlerin çoğu, kompleks çarpık ayak deformitelerinin sadece bir komponentinin düzeltilmesine yöneliktir. Çarpık ayakta her bir deformite için özgün tedavi teknikleri ortaya konmuş olmakla beraber, bu hastalarda biçim bozuklukları basit değil karmaşık olduğu için, literatürde kesin cerrahi kriterler belirlenememiştir (Tablo 1). Kemik ameliyatları ile yumuşak doku gevşetmelerinin birlikte uygulandığı girişimler, reoperasyon yapılacak ayakta tehlikeli olabilir. Diğer bir sorun, hastanın yaşıdır. Eğer çocuklar 4-12 yaş arasında ise, yumuşak doku gevşetme girişimleri için büyük ve üçlü osteotomi için küçüktürler.

McHale ve Lenhart tarafindan rapor edilen, mediyal küneiformda açılan kama osteotomisi ve küboidde kapanan kama osteotomisi, bu kompleks deformiteye uygun bir yaklaşım olmakla birlikte, ancak adduksiyonu ve hafif kavus deformitesi olan olgularda kullanılmalıdır. Bu teknikte 2. ve 3. küneiform kemiklerde osteotomi yapılmadığı için (düzelmeyi engelleyici kilitleyici blok), orta ve ciddi derecelerdeki rotasyonel

Tablo 1. Çarpık ayakta tekrar cerrahi girişim algoritması

\begin{tabular}{|c|c|}
\hline Revizyon yaşı & Uygulama \\
\hline 6 ay -2 yıl & $\begin{array}{l}\text { 1. Tekrar yumuşak doku gevşetmesi } \\
\text { - Plantar cilt katlantısı belirgin ise; plantar gevşetme eklenir. } \\
\text { - Ayak önü adduksiyonu düzelmemişse; kapsülotomiler eklenir. }\end{array}$ \\
\hline $2-4$ yıl & $\begin{array}{l}\text { 1. Tekrar yumuşak doku gevşetmesi } \\
\text { 2. Plantar cilt katlantısı belirgin ise; plantar gevşetme eklenir. } \\
\text { 3. Ayak önü adduksiyonu düzelmemişse; } \\
\text { a. Kapsülotomiler } \\
\text { b. Kalkaneoküboid eklem kıkırdak eksizyonu } \\
\text { c. Küboid dekansellektomi eklenir. }\end{array}$ \\
\hline $4-8$ yıl & $\begin{array}{l}\text { 1. Tekrar yumuşak doku gevşetmesi } \\
\text { 2. Plantar cilt katlantısı belirgin ise; plantar gevşetme eklenir. } \\
\text { 3. Ayak önü adduksiyonu tam düzelmemişse } \\
\text { a. Kapsülotomiler } \\
\text { b. Kalkaneoküboid eklem füzyonu (Dilwyn-Evans) } \\
\text { c. Distal kalkaneus eksizyonu } \\
\text { d. Küboid dekansellasyonu } \\
\text { e. 1. küneiform açılan kama osteotomisi } \\
\text { f. Tarsometatarsal kapsülotomiler } \\
\text { g. Metatarsal osteotomiler } \\
\text { 4. Zayıf peroneal, güçlü tibialis anterior varsa } \\
\text { a. Tibialis anterior transferi } \\
\text { b. Tibialis anterior split transferi } \\
\text { 5. Topuk varusu düzelmemişse; Dwyer osteotomisi eklenir. }\end{array}$ \\
\hline
\end{tabular}

8 yaş üstü 1. Tekrar yumuşak doku gevşetmesi

2. Plantar cilt katlantısı belirgin ise; plantar gevşetme eklenir.

3. Topuk varusu düzelmemişse; Dwyer osteotomisi eklenir.

4. Ayak önü adduksiyonu tam düzelmemişse

a. Kalkaneoküboid eklem füzyonu (Dilwyn-Evans)

b. Distal kalkaneus eksizyonu

c. Küboid dekansellasyonu

d. Metatarsal osteotomiler

5. Kavus; midtarsal osteotomi

6. Distraksiyon osteogenezisi (Ilizarov)

7. Üçlü artrodez (10 yaşüstü)

8. Supramalleolar tibial osteotomi 


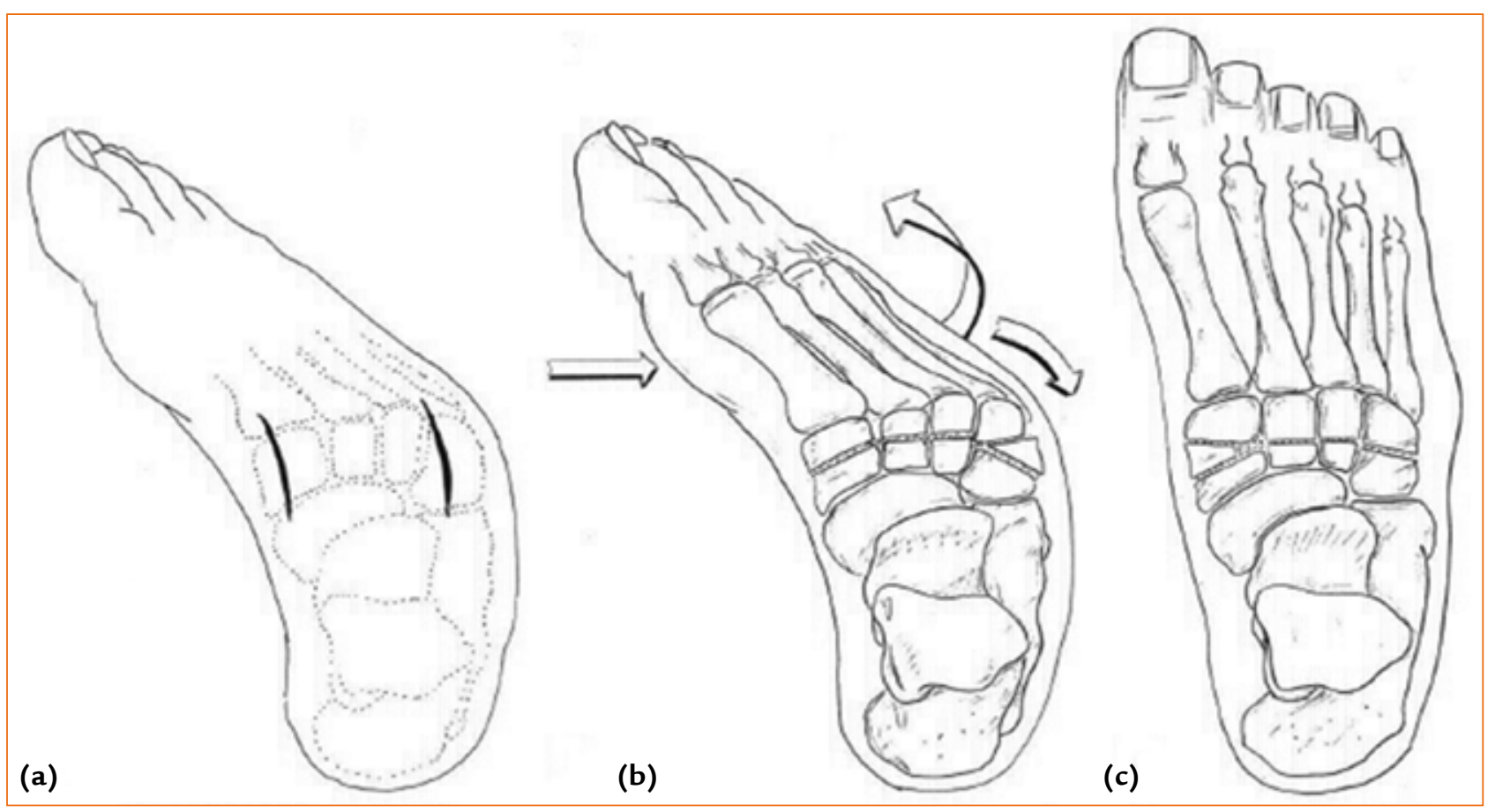

Şekil 1. Fasulye biçiminde ayak deformitesinde trans-midtarsal osteotomi uygulaması.

deformiteleri ve kavusu düzeltemez. Gupta ve Kumar ile Wilcox ve Weitler, tanımladıkları girişimnde transvers dorsal insizyon kullanmışlardır. Böyle geniş bir transvers insizyondan kaçınmak gerekir çünkü bu, dorsalis pedis arterinin üzerinden geçer ve tehlikelidir. Ayrıca, bu teknikler lateral kolonu kısaltıp mediyal kolonu uzatmaz. Amaç, ayağın lateral ve mediyal kolonlarının dengelenerek, yeniden dizilimi ile birlikte rotasyonel düzelmeyi elde etmektir.

Sık görülebilen fasulye biçiminde ayaklarla kavovarus deformitelerinde, trans-midtarsal osteotomi uygulanarak biçim bozukluğunun üç boyutlu düzeltilmesi olasıdır. Köse ve arkadaşları tarafından tanımlanan transmidtarsal osteotomi, özellikle kavus ve fasulye biçimli ayak gibi üç boyutlu deformitelerde etkilidir. ${ }^{[12]}$ Cerrahi girişim, hasta sırt üstü yatarken, turnikesiz olarak gerçekleştirilir. Küboid kemik skopi ile lokalize edildikten sonra, ayak sırtında $2 \mathrm{~cm}$ vertikal cilt insizyonu yapılır. Yumuşak doku disseksiyonu, küboid kemik lateral ve dorsalinde yapılır ve kemik subperiosteal olarak açıldıktan sonra, yaklaşık 10-12 mm kama, sırtı dorsolateral pozisyonda olacak biçimde, yassı-keskin bir osteotom ile çıkartılır. Daha sonra, mediyal küneiform kemik benzer biçimde lokalize edilip, ekstansör hallusis longus tendonunun mediyalinde ikinci bir insizyon yapılır. Mediyal küneiform kemikte açılan kama osteotomisi, anterior tibialis tendon yapışma yeri korunarak yapılır. Aynı insizyonlar kullanılarak, orta ve lateral kemiklerde dorsal truncated wedge osteotomisi yapılır. Bu aşamada ayak ön kısmı ile arka kısmı birbirinden tamamen bağımsız hareket edebilir hale gelir. Küboid kemikten alınan kama mediyal küneiformda yapılan açılan osteotomi bölgesine sırtı mediyale gelecek biçimde konur ve bu aşamada rotasyon, adduksiyon ve kavus deformiteleri düzeltilip ayak istenen uygun pozisyonda iken, osteotomi hatları iki Kirschner teli (K-teli) veya U-çivisi ile sabitlenir (Şekil 1). Operasyon sırasında grafi çekilerek tellerin yeri, ve deformitelerdeki düzelme tespit edilir. Önce diz altı sirküler alçı, altı hafta sonra ise yürüme alçısı uygulanır; radyografik kemik iyileşmesi görülene dek (genellikle 10-12 hafta) devam eder. Trans-midtarsal osteotomi, deformitenin tam üzerinde yapıldığı için, daha iyi bir düzelme sağlar ve ayağın orta ve ön kısmında daha yüksek oranda açısal ve rotasyonel düzelmeyi olası kılar. Üç̧ planda aynı anda düzeltme yapılabilir. Osteotomi alanlarındaki geniş yüzeyler iyileşmenin kolay ve sorunsuz olmasını sağlar.

Çarpık ayak deformitesinin hiçbir zaman tamamen normale dönmesi beklenmediği için, sonuçlar tatmin edici olan ve olmayan olarak değerlendirilebilir. Olabildiğince düzgün bir ayak, yere düz basarak ağrısız yürüyüş ve ayak hareketlerinde daha fazla bir azalma olmaması, tatmin edici sonuç kriterleridir. Tatmin edici sonuç, trans-midtarsal osteotomi uygulanan tüm olgularda elde edilmiştir. Bu girişimde kullanılan osteotomi intraartikülerdir ve üç eklemi kat eder; 

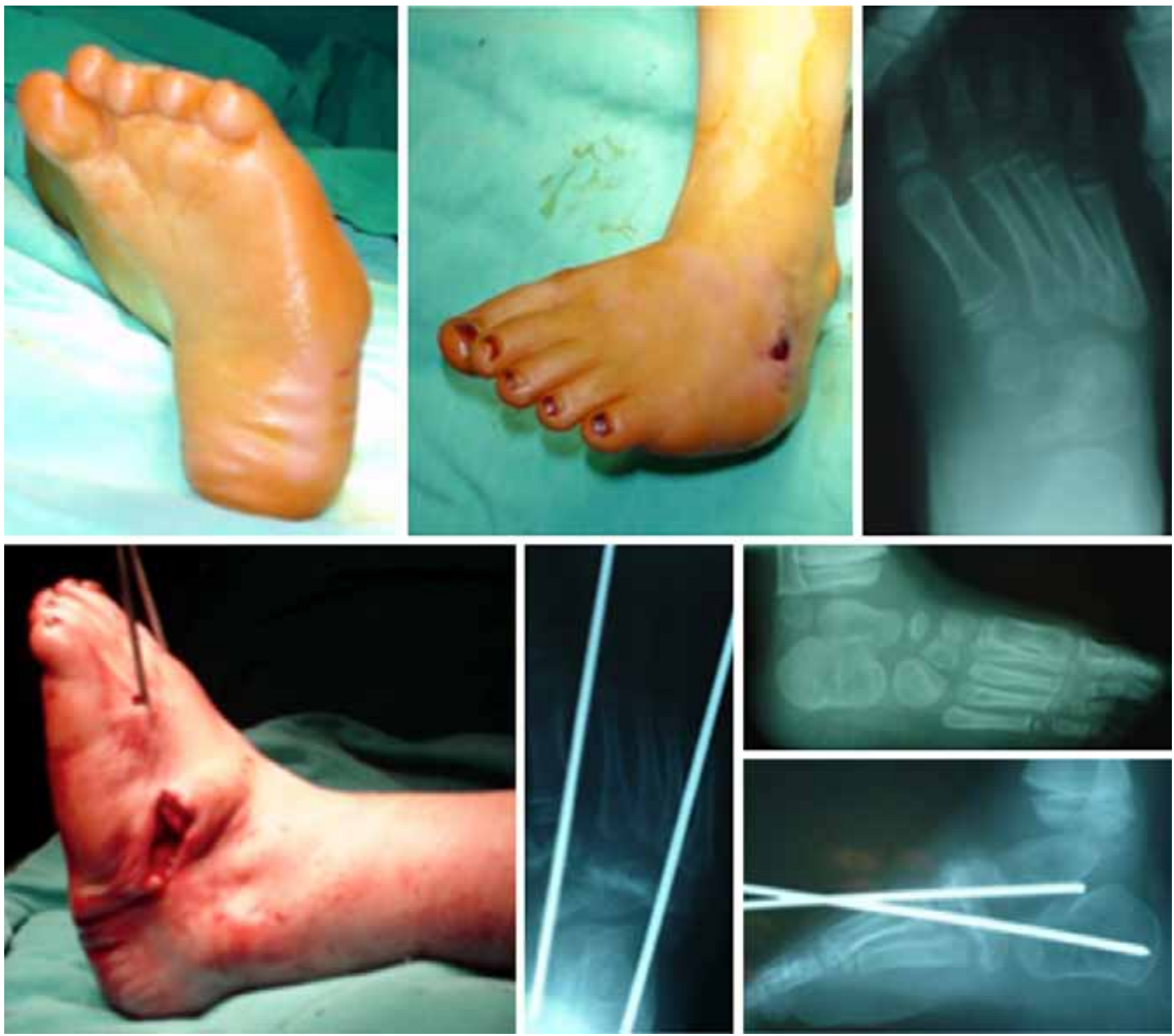

Şekil 2. Trans-midtarsal osteotomi uygulamış yedi yaşında hastada düzelme izlenmekte.

bu nedenle, gelecekte artroz olasılı̆g vardır. Bununla birlikte, ayak arkası ile önü arasındaki hareket, temel olarak Lisfrank hattında olur ve küneiform kemiklerle küboid kemik arasındaki hareket ihmal edilebilecek kadar azdır. Sonuçta, bu girişim ile minimal hareket gözden çıkarılmış olur. Girişim dört yaşından büyük çocuklarda yapılmalıdır; çünkü, iyi gelişmiş tarsal kemikler gereklidir (Şekil 2).

\section{KAYNAKLAR}

1. Thompson GH, Simons GW. Congenital talipes equinovarus (clubfeet) and metatarsus adductus. In: Drennan JC, editor. The child's foot and ankle. 1st ed. New York: Raven Press; 1992. p.97-133.
2. Lehman WB, Atar D. Complications in the management of talipes equinovarus. In: Drennan JC, editor. The child's foot and ankle. New York: Raven Press; 1992. p.135-53.

3. Ritterbusch JF. Pediatric foot. In: Mizel MS, Miller RA, Scioli MW, editors. Foot and Ankle, Orthopaedic Knowledge Update. Rosemont, Illinois: AAOS; 1998. p.65-78.

4. Crawford $\mathrm{AH}$. Congenital clubfoot. In: Richards BS, editor. Orthopaedic Knowledge Update Pediatrics. Rosemont: AAOS, 1996;203-10.

5. Willis RB, Al-Hunaishel M, Guerra L, Kontio K. What proportion of patients need extensive surgery after failure of the Ponseti technique for clubfoot? Clin Orthop Relat Res 2009;467(5):1294-7. CrossRef

6. Parsa A, Moghadam $\mathrm{MH}$, Jamshidi $\mathrm{MH}$. Relapsing and residual clubfoot deformities after the application of the ponseti method: a contemporary review. Arch Bone Jt Surg 2014;2(1):7-10. 
7. Atar D, Lehman WB, Grant AD, Strongwater AM. Surgery for clubfoot and skewfoot; revision clubfoot surgery. In: Jahss $\mathrm{MH}$, editor. Disorders of foot and ankle. Medical and surgical management. 2nd ed. Philadelphia: WB Saunders; 1991. p.830-40.

8. Evans D. Relapsed club foot. J Bone Joint Surg $\mathrm{Br}$ 1961;43-B:722-33.

9. Hjelmstedt A, Sahlstedt B. Role of talocalcaneal osteotomy in clubfoot surgery: results in 31 surgically treated feet. J Pediatr Orthop 1990;10(2):193-7.
10. Toohey JS, Campbell P. Distal calcaneal osteotomy in resistant talipes equinovarus. Clin Orthop Relat Res1985;(197):224-30.

11. Paley D. The correction of complex foot deformities using Ilizarov's distraction osteotomies. Clin Orthop Relat Res 1993;(293):97-111.

12. Köse N, Günal i, Göktürk E, Seber S. Treatment of severe residual clubfoot deformity by trans-midtarsal osteotomy. J Pediatr Orthop B 1999;8(4):251-6. 